\title{
Effect of the microtransplantation of allogeneic hematopoietic stem cells as maintenance therapy for elderly patients with acute leukemia
}

\author{
XIANGJING KONG, YONGSHENG CHEN, LI WANG, YALI ZHOU, YUANYUAN HE, \\ WEIYE NIE, XINHUA ZHANG and XIAOLIN YIN \\ Department of Hematology, 303rd Hospital of The People's Liberation Army, Nanning, Guangxi 530021, P.R. China
}

Received June 21, 2014; Accepted February 10, 2015

DOI: $10.3892 / \mathrm{ol} .2015 .2995$

\begin{abstract}
The incidence of acute myeloid leukemia (AML) increases with age. Elderly patients with AML are less tolerant to high-intensity consolidation therapy than younger patients, with significantly worse prognoses. Induction and consolidation therapy combined with allogeneic hematopoietic stem cell microtransplantation may improve the prognosis of elderly patients with AML. The present study reports the effect of maintenance therapy with low-dose chemotherapy treatment combined with microtransplantation in elderly patients with AML following consolidation. Between January 2011 and April 2014, three elderly patients (>55 years old), including one 58-year-old patient with acute mixed lineage leukemia (AMLL) and two patients with AML aged 59 years and 62 years, underwent microtransplantation maintenance therapy. Following a complete response to induction chemotherapy and consolidation chemotherapy with two to four cycles of medium dose Ara-c (auto transplantation was performed in the patient with AMLL), maintenance therapy was performed using low-dose Ara-c combined with human leukocyte antigen haploidentical allogeneic hematopoietic stem cell microtransplantation, which was repeated every 3 to 6 months. The patients were followed up for 27, 20 and 16 months, respectively, and all three patients achieved disease-free survival. The bone marrow Wilms' tumor suppression gene (WT1) level of the case with AMLL was dynamically monitored. The results showed that the WT1 level was abnormally high prior to microtransplantation and gradually declined to normal levels subsequent to the process. None of the patients suffered from graft versus host disease during the microtransplantation process. In conclusion, microtransplantation maintenance therapy following consolidation therapy is feasible in elderly patients with AML, and is expected to be
\end{abstract}

Correspondence to: Professor Xiaolin Yin, Department of Hematology, 303rd Hospital of The People's Liberation Army, 52 Plant Road, Nanning, Guangxi 530021, P.R. China

E-mail: yin-x1@163.com

Key words: microtransplantation, acute myeloid leukemia, elderly, maintenance able to further remove residual lesions and improve treatment efficacy. A large-scale clinical trial is required to confirm the effect of maintenance therapy in elderly patients with AML.

\section{Introduction}

The incidence of acute myeloid leukemia (AML) increases with age. Elderly patients have gradually become the main individuals affected by AML due to an ageing population. AML patients in developed countries are diagnosed at an average age of 71 years (1). Typically, the threshold for leukemia in elderly patients is considered to be between 55 and 65 years old (2). The prognosis in patients $<50$ years old has been found to be significantly different from that in patients between 50 and 65 years old (3). Compared with younger patients, elderly patients with AML exhibit more karyotypes associated with a poor prognosis $(4,5)$, higher expression rates of gene mutations associated with drug resistance (6), and are more frequently secondary to myelodysplastic syndrome $(7,8)$. Therefore, the prognosis of patients with AML declines with age. The median overall survival (OS) time of AML patients aged 16-55, 56-65, $66-75$ and $\geq 75$ years has been recorded as $1,119,359,180$ and 80 days, respectively (1).

In 2010, Guo et al (9) first reported that the 2-year OS rate in elderly patients with AML increased from 11 to $39 \%$ with fractional infusion of small amounts of allogeneic hematopoietic stem cells (microtransplantation) following chemotherapy. Microtransplantation was reported to have anti-leukemic effects and promoted hematopoietic recovery $(9,10)$. Although the prognosis in elderly patients with AML has been significantly improved by microtransplantation combined with chemotherapy, it remains inferior compared with that in young patients. For AML patients $<65$ years old, when microtransplantation was added to chemotherapy, the 6-year OS rate for low- and medium-risk patients reached 89.5 and $65.2 \%$, respectively (10). These results indicate that there is room for improvement in the efficacy of this treatment paradigm in elderly patients with AML. To accomplish this, maintenance therapy by low-dose chemotherapeutic treatment combined with microtransplantation was performed in three elderly patients ( $>55$ years old) with leukemia, and the findings are reported in the present study. 


\section{Patients and methods}

Patients. Three elderly patients with acute leukemia, consisting of two cases of AML and one case of acute mixed lineage leukemia (AMLL), were admitted to the Department of Hematology of the 303rd Hospital of the People's Liberation Army (PLA; Nanning, Guangxi, China) between January 2011 and January 2014. Microtransplantation is characterized by a smaller number of transfused stem cells ( 1/3-1/4 of the dosage compared with allogeneic hematopoietic stem cell transplantation) in addition a pre-conditioning regime is unecessary. Therefore, for elderly patients, microtransplantation apears to be more tolerable than allogeneic hematopoietic stem cell transplantation, which also has a higher financial cost for treatment. Microtransplantation was performed in all patients once informed consent had been obtained, and under the approval of the Medical Ethics Committee of the 303rd Hospital of the PLA.

Mobilization and collection of peripheral blood stem cells. Healthy donors were selected, with preference for haplo-identical human leukocyte antigen-matched donors. Recombinant human granulocyte colony-stimulating factor (Kirin-Sankyo Co., Ltd., Tokyo, Japan) was subcutaneously injected at a dose of $5 \mu \mathrm{g} / \mathrm{kg} /$ day to mobilize the peripheral blood stem cells daily for 5 days. The peripheral blood stem cells were collected on days 5 and 6 with CS-3000 plus blood cell separators (Baxter Healthcare Ltd., Berkshire, UK).

Maintenance therapy regimes. As detailed in Table I, all patients received maintenance treatment following complete response (CR) induction and intensified consolidation chemotherapy. For the patients who received chemotherapy, donor stem cell infusion was performed at $36 \mathrm{~h}$ post-chemotherapy. In total, $2-4 \times 10^{8} / \mathrm{kg}$ mononuclear cells were infused each time. Single-dose $5 \mathrm{mg}$ dexamethasone was used to prevent allergy. Other immunosuppressants for the prevention of graft versus host disease (GVHD) were not used.

Evaluation of efficacy and adverse reactions. CR was defined by the presence of $<5 \%$ bone marrow blasts, no extramedullary infiltration of leukemic cells and normal results in the peripheral hemocyte analysis. The follow-up deadline was April 30, 2014. Disease-free survival (DFS) was defined as the duration from $\mathrm{CR}$ induction to the follow-up deadline.

\section{Results}

General data. The three patients were aged between 58 and 62 years old and consisted of two males and one female. The detailed diagnosis and treatment processes of the three cases are shown in Table I.

Treatment efficacy. The detailed treatment process of the patient with AMLL has previously been reported (11), and the patient was further followed in the present study. In brief, subsequent to autologous stem cell transplantation and sequential allogeneic hematopoietic stem cell microtransplantation, the patient had achieved DFS for 27 months. The bone marrow WT1 levels in the patient decreased following microtransplantation and declined more significantly with an increased number of courses of microtransplantation (Fig. 1). Upon reexamination in April 2014, the patient maintained the CR state.

Cases 2 and 3 were AML patients with intermediate-risk in chromosomal and molecular biological evaluations. The two patients achieved CR induction using a combined treatment paradigm of daunorubicin, arabinosylcytosine (Ara-C) and etoposide (also known as the DAE regimen). Following the DAE regimen treatment, medium-dose Ara-C $\left(1.0-1.5 \mathrm{~g} / \mathrm{m}^{2}\right.$ every $12 \mathrm{~h}$ on days 1,3 and 5$)$ and combined Ara-C $\left(0.5-1.0 \mathrm{~g} / \mathrm{m}^{2}\right.$ every $12 \mathrm{~h}$ on days 1,3 and 5 ) and etoposide $\left(50-70 \mathrm{mg} / \mathrm{m}^{2}\right.$ every $12 \mathrm{~h}$ on days 1, 3 and 5) was alternatively used for consolidation treatment (referred to as AE treatment). The donor stem cells were infused at $36 \mathrm{~h}$ post-chemotherapy. After two to four courses of consolidation treatment by medium-dose Ara-C/AE, chemotherapy prior to microtransplantation was changed to medium-dose Ara-C (0.5-1.0 g/ $\mathrm{m}^{2}$ every $12 \mathrm{~h}$ on days 1,3 and 5) or standard Ara-C $\left(0.4 \mathrm{~g} / \mathrm{m}^{2}\right.$ every $12 \mathrm{~h}$ on days 1,3 and 5$)$ with an interval of 4-5 months. The last follow-up showed that the two patients remained disease-free.

Adverse effects. Of the 17 times that microtransplantation treatment was administered in the three patients, discomforts such as fever and diarrhea were not observed. A transient rash and pruritus occurred twice during transfusion and the patients recovered without treatment.

\section{Discussion}

For elderly AML patients aged 55-65 years, even intensive chemotherapy has been shown to only achieve an average OS time of 530 days, which is considerably shorter than the 2,546 days observed in patients $<55$ years old (1). For those patients with intermediate-risk AML, the average OS time is only 12 months (12). The prognosis of patients with AMLL is worse than that of elderly patients with AML, with a median survival time of only 9 months if chemotherapy only was recommended (13). Of the three patients in the present study, one case with AMLL was treated by autologous transplantation followed by microtransplantation as maintenance therapy and two cases with intermediate-risk AML were treated and maintained by microtransplantation combined with chemotherapy. All three patients achieved a DFS time of $>16$ months (mean, 21 months), suggesting that maintenance with microtransplantation combined with chemotherapy could improve the prognosis in elderly patients with AML. These results were consistent with the results from the study by Guo et al $(9,10)$. The study found that the 2 year OS and event free survival (EFS) rates in elderly patients with AML treated by chemotherapy combined with microtransplantation were increased significantly compared with those of patients treated by chemotherapy alone.

Typically, maintenance therapy is not recommended for patients with AML. In a study consisting of 789 AML patients aged 15-64 years, patients post-CR induction were randomly divided into a group administered four cycles of standard chemotherapy consolidation and a group administered maintenance after three cycles of standard chemotherapy consolidation. The results showed that there was no significant difference in the DFS and progression-free survival rates between the two groups, suggesting that patients who completed intensive 
Table I. General conditions and microtransplantation efficacy in three patients treated by microtransplantation.

\begin{tabular}{|c|c|c|c|}
\hline Parameter & Patient 1 & Patient 2 & Patient 3 \\
\hline \multicolumn{4}{|l|}{ Patient data } \\
\hline Gender & Male & Female & Male \\
\hline Age, years & 59 & 58 & 62 \\
\hline Karyotype & $46(X, Y)$ & $46(X, X)$ & $46(X, Y)$ \\
\hline Fused genes & - & - & - \\
\hline Diagnosis & AMLL & AML-M5b & AML-M5b \\
\hline \multicolumn{4}{|l|}{ Donor data } \\
\hline Sources & Son & Son & Son \\
\hline Age, years & 33 & 31 & 29 \\
\hline Blood types of donors/recipients & $\mathrm{O} / \mathrm{O}$ & $\mathrm{O} / \mathrm{O}$ & $\mathrm{B} / \mathrm{B}$ \\
\hline HLA matching of donors and recipients & $3 / 6$ & $4 / 6$ & $3 / 6$ \\
\hline Number of stem cell collections & 1 & 2 & 1 \\
\hline Date of stem cell collection in donors & 2012.01 & $2012.11 / 2013.05$ & 2013.04 \\
\hline \multicolumn{4}{|l|}{ Cell counts } \\
\hline MNC (108/kg recipient) & 1.3 & 15.5 & 2.9 \\
\hline $\mathrm{CD}^{+} 4^{+}(106 / \mathrm{kg}$ recipient $)$ & 0.652 & 5.2 & 1.5 \\
\hline \multicolumn{4}{|l|}{ Efficacy of microtransplantation } \\
\hline Chemotherapy prior to maintenance & $\begin{array}{c}\text { Medium-dose } \\
\text { Ara-C } \pm \text { MTX/VP-16 } \\
\text { followed by auto-HSCT }\end{array}$ & $\begin{array}{l}\text { Medium-dose } \\
\text { Ara-C } \pm \text { VP-16 }\end{array}$ & $\begin{array}{l}\text { High-dose } \\
\text { Ara-C }{ }^{c}\end{array}$ \\
\hline $\begin{array}{l}\text { Chemotherapy prior to microtransplantation } \\
\text { during maintenance }\end{array}$ & $\begin{array}{l}\text { Medium-dose } \\
\text { Ara-C }^{\mathrm{a}}\end{array}$ & $\begin{array}{l}\text { Standard-dose } \\
\text { Ara-C }{ }^{c}\end{array}$ & $\begin{array}{l}\text { Standard-dose } \\
\text { Ara- } C^{b}\end{array}$ \\
\hline Courses of microtransplantation, $\mathrm{n}$ & 5 & 7 & 5 \\
\hline Efficacy & $\mathrm{CR}$ & $\mathrm{CR}$ & CR \\
\hline Outcome & DFS, 27 months & DFS, 20 months & DFS, 16 months \\
\hline
\end{tabular}

Chemotherapy was administered for ${ }^{\mathrm{a}}$ one, ${ }^{\mathrm{b}}$ two, ${ }^{\mathrm{c}}$ three or ${ }^{\mathrm{d}}$ four cycles. AMLL, acute mixed linage leukemia; AML, acute myeloid leukemia; MNC, mononuclear cell; CD34, cluster of differentiation 34; VP-16, etoposide; MTX, methotrexate; HSCT, hematopoietic stem cell transplantation; CR, complete response; DFS, disease-free survival.

consolidation may not benefit from maintenance therapy (14). However, elderly patients with AML often cannot tolerate high-dose chemotherapy owing to their declining physical health. In a study of patients with AML aged 46-60 years, the increased intensity of consolidation treatment following CR induction reduced the relapse rate, but the benefits were counteracted by increased treatment-related mortality and the overall survival rate was not improved, compared with the conventional consolidation group (15). Buchner et al (16) randomly divided 832 AML patients who were $>16$ years of age into an intensive treatment group and a maintenance treatment group. The Ara-c dose in the consolidation program used in the patients $>60$ years of age was adjusted from 3 to $1 \mathrm{~g} / \mathrm{m}^{2}$, and the results showed that the patients $>60$ years of age benefited from the maintenance therapy. Ferrero et al (17) also found that maintenance therapy for patients with AML who were unsuitable for chemotherapy could reduce the recurrence rate and improve the long-term survival rate. Therefore, elderly patients with AML may be more dependent on maintenance therapy to reduce the incidence of relapses and improve the prognosis, as the low intensity of chemotherapy during consolidation treatment may not be high enough to eradicate residual leukemia.

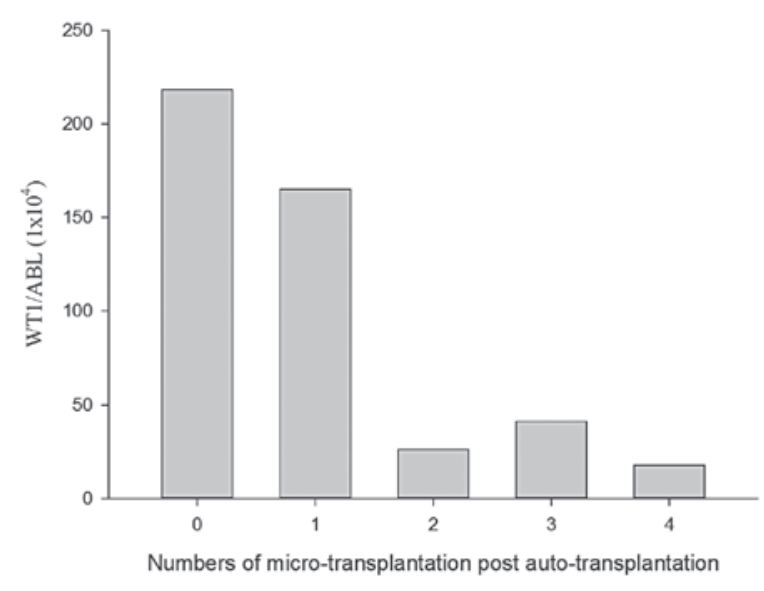

Figure 1. Dynamic changes of WT1 levels during maintenance treatment. WT1 levels were abnormally increased ( $>140 / 1 \times 10^{4}$ ABL copy number) pior to microtransplantation. Following microtransplantation, the WT1 levels gradually decreased to the normal range.

Lowenberg et al (18) administered maintenance therapy by low-dose Ara-C in elderly AML patients. The results showed that the DFS rate of the patients was significantly 
improved, but that the OS rate was not, as the non-relapse mortality rate in the maintenance group was increased. Microtransplantation of allogeneic hematopoietic stem cells may not only promote hematopoietic recovery and improve the tolerance to chemotherapy, but it may also activate specific anti-leukemia effects in elderly patients $(9,10)$. We hypothesized that microtransplantation may be more feasible and effective in maintenance therapy for elderly patients with AML. Treatment-related mortality was not observed in the three patients who received the maintenance therapy of microtransplantation combined with low-dose chemotherapy following intensive therapy in the present study. WT1 could be used as an indicator of residual disease, and an increase in WT1 level may indicate early relapse (19). In the present study, during the maintenance therapy, dynamic changes in the WT1 level were monitored in one patient. The results showed that the WT1 level gradually declined with an increasing number of microtransplantations, confirming that maintenance therapy with microtransplantation could be effective in eradicating residual disease. During the course of maintenance therapy using microtransplantation, no patient suffered from GVHD, suggesting that microtransplantation was safe to use as maintenance therapy.

\section{References}

1. Juliusson G, Antunovic P, Derolf A, et al: Age and acute myeloid leukemia: real world data on decision to treat and outcomes from the Swedish Acute Leukemia Registry. Blood 113: 4179-4187, 2009.

2. Vey N: Targeting age-related changes in the biology of acute myeloid leukemia: is the patient seeing the progress? Interdiscip Top Gerontol 38: 73-84, 2013.

3. Yanada M, Ohtake S, Miyawaki S, et al; Japan Adult Leukemia Study Group: The demarcation between younger and older acute myeloid leukemia patients: a pooled analysis of 3 prospective studies. Cancer 119: 3326-3333, 2013.

4. Shimoni A, Kroger N, Zabelina T, et al: Hematopoietic stem-cell transplantation from unrelated donors in elderly patients (age $>55$ years) with hematologic malignancies: older age is no longer a contraindication when using reduced intensity conditioning. Leukemia 19: 7-12, 2005.

5. Lazarevic V, Horstedt AS, Johansson B, et al: Incidence and prognostic significance of karyotypic subgroups in older patients with acute myeloid leukemia: the Swedish population-based experience. Blood Cancer J 4: e188, 2014.

6. Leith CP, Kopecky KJ, Chen IM, et al: Frequency and clinical significance of the expression of the multidrug resistance proteins MDR1/P-glycoprotein, MRP1 and LRP in acute myeloid leukemia: a Southwest Oncology Group Study. Blood 94: 1086-1099, 1999.

7. Leone G, Mele L, Pulsoni A, Equitani F and Pagano L: The incidence of secondary leukemias. Haematologica 84: 937-945, 1999.
8. Ostgård LS, Kjeldsen E, Holm MS, et al: Reasons for treating secondary AML as de novo AML. Eur J Haematol 85: 217-226, 2010.

9. Guo M, Hu KX, Yu CL, et al: Infusion of HLA-mismatched peripheral blood stem cells improves the outcome of chemotherapy for acute myeloid leukemia in elderly patients. Blood 117: 936-941, 2011.

10. Guo M, Hu KX, Liu GX, et al: HLA-mismatched stem-cell microtransplantation as postremission therapy for acute myeloid leukemia: long-term follow-up. J Clin Oncol 30: 4084-4090, 2012.

11. Chen YS, Kong XJ, Zhang XH and Yin XL: Treatment of acute mixed-cell leukemia with autologous hematopoietic SCT followed by allogeneic hematopoietic stem cell micro-transplantation. Bone Marrow Transplant 49: 984-985, 2014.

12. Appelbaum FR, Gundacker H, Head DR, et al: Age and acute myeloid leukemia. Blood 107: 3481-3485, 2006.

13. Al-Seraihy AS, Owaidah TM, Ayas M, El-Solh H, Al-Mahr M, Al-Ahmari A and Belgaumi AF: Clinical characteristics and outcome of children with biphenotypic acute leukemia. Haematologica 94: 1682-1690, 2009.

14. Miyawaki S, Sakamaki H, Ohtake S, et al; Japan Adult Leukemia Study Group AML 97 Study: A randomized, postremission comparison of four courses of standard-dose consolidation therapy without maintenance therapy versus three courses of standard-dose consolidation with maintenance therapy in adults with acute myeloid leukemia: the Japan Adult Leukemia Study Group AML 97 Study. Cancer 104: 2726-2734, 2005.

15. Hengeveld M, Suciu S, Karrasch M, et al: Intensive consolidation therapy compared with standard consolidation and maintenance therapy for adults with acute myeloid leukaemia aged between 46 and 60 years: final results of the randomized phase III study (AML 8B) of the European Organization for Research and Treatment of Cancer (EORTC) and the Gruppo Italiano Malattie Ematologiche Maligne dell'Adulto (GIMEMA) Leukemia Cooperative Groups. Ann Hematol 91: 825-835, 2012.

16. Büchner T, Hiddemann W, Berdel WE, et al; German AML Cooperative Group: 6-Thioguanine, cytarabine and daunorubicin (TAD) and high-dose cytarabine and mitoxantrone (HAM) for induction, TAD for consolidation and either prolonged maintenance by reduced monthly TAD or TAD-HAM-TAD and one course of intensive consolidation by sequential HAM in adult patients at all ages with de novo acute myeloid leukemia (AML): a randomized trial of the German AML Cooperative Group. J Clin Oncol 21: 4496-4504, 2003.

17. Ferrero D, Crisà E, Marmont F, et al: Survival improvement of poor-prognosis AML/MDS patients by maintenance treatment with low-dose chemotherapy and differentiating agents. Ann Hematol 93: 1391-1400, 2014

18. Löwenberg B, Suciu S, Archimbaud E, et al: Mitoxantrone versus daunorubicin in induction-consolidation chemotherapy - the value of low-dose cytarabine for maintenance of remission, and an assessment of prognostic factors in acute myeloid leukemia in the elderly: final report. European Organization for the Research and Treatment of Cancer and the Dutch-Belgian Hemato-Oncology Cooperative Hovon Group. J Clin Oncol 16: 872-881, 1998.

19. Polák J, Hájková H, Maalaufová-Soukupová J, et al: Estimation of molecular upper remission limit for monitoring minimal residual disease in peripheral blood of acute myeloid leukemia patients by WT1 expression. Exp Ther Med 3: 129-133, 2012. 